IBIMA Publishing

Journal of e-Government Studies and Best Practices

http://www.ibimapublishing.com/journals/JEGSBP/jegsbp.html

Vol. 2016 (2016), Article ID 542264, 20 pages

DOI: $10.5171 / 2016.542264$

Research Article

\title{
Evaluating the Effectiveness of Biometric Technologies in Controlling the Border Ports of the State of Kuwait Adel Ismail Al-Alawi ${ }^{1}$, Raeed Khalid E. Al-Faresi ${ }^{2}$ and Refaat Hassan Abdel-Razek ${ }^{3}$ \\ ${ }^{1}$ University of Bahrain, College of Business Administration, Department of Management and Marketing P.O., Kingdom of Bahrain \\ ${ }^{2}$ Ministry of Defence, Military of Engineering Projects, Administration Development IT Al-Jewan, State of Kuwait \\ ${ }^{3}$ Department of Industrial Engineering and Engineering Management, College of Engineering, University of Sharjah, United Arab Emirates
}

Correspondence should be addressed to: Adel Ismail Al-Alawi; adel.alalawi@gmail.com

Received date: 22 September 2015; Accepted date: 22 June 2015; Published date: 19 July 2016

Academic Editor: Lian Kee Phua

Copyright (C) 2016. Adel Ismail Al-Alawi, Raeed Khalid E. Al-Faresi and Refaat Hassan Abdel-Razek. Distributed under Creative Commons CC-BY 4.0

\begin{abstract}
Governmental authorities worldwide are continuously searching for the best technology to secure their country s borders. Although several technologies were introduced to Kuwait border ports, the literature showed a lack of published work regarding the evaluation of the effectiveness of biometric mechanism (BTMs) in Kuwait the objective of this study is to identify and evaluate the effectiveness of the BTMs were established. A questionnaire was designed and distributed .Field visits were carried out.A sample size of 268 employees from the security sector of border ports (SSBP) of the three border ports of Kuwait; in addition to employees from the general department of criminal evidence (GDCE) were selected. A total of 262 responses were received and analysed. GDCE and SSBP strongly agreed that BTM is effective in job performance. The individuals in GDCE and SSBP expressed that the fingerprint was the most effective BTM and the best in controlling border ports. The results also showed that some of the individuals in the GDCE and SSBP had inadequate knowledge on BTMs' concept. The current security technologies in SSBP were: the traditional security system, fraud passport detector and fingerprint mechanism. Kuwait international Airport used these three mentioned technologies, while the land ports and seaport used the traditional security system only. Moreover, fingerprint mechanism is newly introduced at Kuwait international Airport. The use of fingerprint decreased the number of illegal entry from expellees who tried to re-enter the country. regarding the evaluation of BTM factors " Knowledge,time,performance,accuracy and reliability" ; the results showed that GDCE considered fingerprint mechanism the best BTM and came in the first place with an approval rate of $49,8 \%$,retinal mechanism came in the third place with $23,3 \%$.in addition the results showed that SSBP considered fingerprint the best BTM and came in the first place with an approval rate of $47.5 \%$,iris recognition came in the second place with $31.8 \%$ and retinal came in the third place with $24.8 \%$. Therfore, GDCE and SSBP considered fingerprint the most effective and the best in controlling the border ports of the state of Kuwait ; and came in the first place with $48.4 \%$ through the evaluation of all BTM factors, while iris and retinal came in the second place with $26.9 \%$ and $26.6 \%$ respectively, while facial came in the third place with $17.7 \%$.It is concluded that BTMs are more effective than traditional methods and they are highly demanded and recommended by GDCE and SSBP to control the border ports of the state of Kuwait.
\end{abstract}

Keywords: Mechanisms, Identification, Verification,Authentication, False rejection rate, False acceptance rate.

Cite this Article as: Adel Ismail Al-Alawi, Raeed Khalid E. Al-Faresi and Refaat Hassan Abdel-Razek (2016)," Evaluating the Effectiveness of Biometric Technologies in Controlling the Border Ports of the State of Kuwait", Journal of e-Government Studies and Best Practices, Vol. 2016 (2016), Article ID 542264, DOI:10.5171/2016.542264 


\section{Introduction}

Security has become a vital yet complex issue for many countries due to the strategic challenges related to national security. Since the terrorist attack of 11 September 2001 in the United States, security and identification management are at the top of the agenda in many countries. Governmental authorities worldwide are continuously searching for the best technology to secure their country's borders. It has been found in many literature reviews for example (Hosein, 2005; Amoore, 2006; Nabti and Bouridane, 2008; Al-Raisi and Al-Khouri, 2008; Liu, 2009) that biometric recognition technology (BRT) is the best key strategic solution for security and identification management. . Thus, as stated by Shaikh and Rabaiotti (2010), "Biometric-based identity management is increasingly being used by governments and national agencies, amongst others, for identity verification and law enforcement".

Kuwaitis, visitors and expatriates come into Kuwait through various points of entry, such as Kuwait International Airport and Al-Nowaiseeb land port that are considered the busiest ports in Kuwait. This requests prompt and accurate identification of individuals. Issues such as illegal immigrants, the war on terror, expulsions, and duplicate identity fraud are all security issues that challenge the authorities in the State of Kuwait. In addition, there are repeated attempts of former expellees who are foreign nationals to re-enter the country after being expelled for various violations. BTM was introduced to Kuwait Airport. This necessitates the use of technology to facilitate the managerial tasks and procedures to produce more accurate results. Several technologies were introduced in these parts. There is lack of published work to evaluate the efficiency of BTM in Kuwait.

Therefore, application of such technology helps to minimize the attempts of illegal immigrants and former expellees to reenter the country. In addition, such identification would be an integral part of procedures to aid in preventing terrorist infiltration through faulty boarder clearance procedures thus decreasing the chances of attempts to spread out instability in the country. Moreover, BTM can be utilized to improve identity management procedures and increase the accuracy in carrying out tasks of identity management proficiently, and if utilized in conjunction with an additional identification factor, identification is further fortified.

This research is designed to give an overview of the importance of the use of increased BT at ports of entry in today's mobile world, and specifically to answer the question: How can the Ministry of Interior (MOI) in Kuwait utilize biometric technology mechanism (BTM) in order to improve immigration and population surveillance and pre-emption at its border points of entry?

\section{Research Questions}

This study aims to answer the following questions:

A. What are the opinions of the participants in BTM and their knowledge familiarities of (BTM), awareness and the efforts from the General Department of Criminal Evidence (GDCE) and Security Sector of Border Ports (SSBP) to apply in their organization?

B. Which BTM method is mostly used at the border ports of Kuwait?

C. What is the assessment of the respondents of the BTMs in terms of the following factors: Knowledge familiarity, Time, Performance, Accuracy and Reliability?

\section{Research Objectives}

The aim of this study is to identify and evaluate BTMs in order to improve immigration, population surveillance and pre-emption in the border ports of the State of Kuwait, in order to insure and reach high security level for the country. 
The objectives of this research are as follows:

Investigate and identify the latest modern methods and technologies used in controlling border ports in the State of Kuwait.

Evaluate the current methods and technologies that are used at the Security Sector of Border Ports (SSBP) and the General Department of Criminal Evidence (GDCE) in the State of Kuwait.

\section{Background}

The term biometrics itself is derived from the Greek words bios (life) and metrikos (measurement). Biometrics stand for automated methods of recognizing an individual based on measurable biological and behavioural characteristics. The recognition comes through measuring and analysing the human physiological and behavioural characteristics.

\section{Identification and Verification}

The identification process involves a comparison between the real-time biometric identification and the templates stored in the database including all individuals' data "one-to-many", while a verification process is the comparison between the captured data which are identified, and the template that existed in the database, to verify a person "one-toone" (Nabti and Bouridane, 2008).

\section{Authentication}

Authentication is an automated process; where the identity of an individual is CONFIRMED through analyzing unique characteristics (Poli et al., 2009).

\section{Criteria when Evaluating Different Biometrics Technologies}

According to Al-Raisi and Al-Khouri (2008), the desired biometric system should be capable of scanning all incoming arrivals and provide positive or negative hit feedback.
A. The ability of identifying a single person from a large population of people.
B. Ease of use.
C. Does not change over time.
D. Quick response time.
E. Suitable for mass transit locations, (e.g., Airports.).
F. Safe and no medical side effects (disease control).
G. Is affordable.

\section{The Main Factors of BTMs Evaluation}

Some criteria can be considered as factors in evaluating BTMs. These factors include: Time, Performance, Accuracy and Reliability. Moreover, the researcher considers BTM factors (Knowledge - TimePerformance- Accuracy and reliability) for the evaluation of BTMs in this study based on the findings and understanding from the literature reviews showed in table (1) and Figure (1).

Table 1: Evaluation factors of BTMs

\begin{tabular}{|c|c|c|c|c|}
\hline \multicolumn{5}{|c|}{ EVALUATION FACTORS OF BTMs } \\
\hline Knowledge & Time & Performance & Accuracy & Reliability \\
\hline Familiarity & Enrolment & Weather conditions & Identification & \multirow{5}{*}{ Konwledge \& User Acceptance } \\
\hline Efforts \& Concepts & Transaction & Enviorement Condtions & Any Location & \\
\hline \multirow{3}{*}{ Attitude\&Perseptions } & Congestion & Travelares \& Citizens less resistance & FRR & \\
\hline & Consumi & Mass Transit Locations & \multirow{2}{*}{ FAR } & \\
\hline & consuming & Safty \&Non-Invasive & & \\
\hline
\end{tabular}




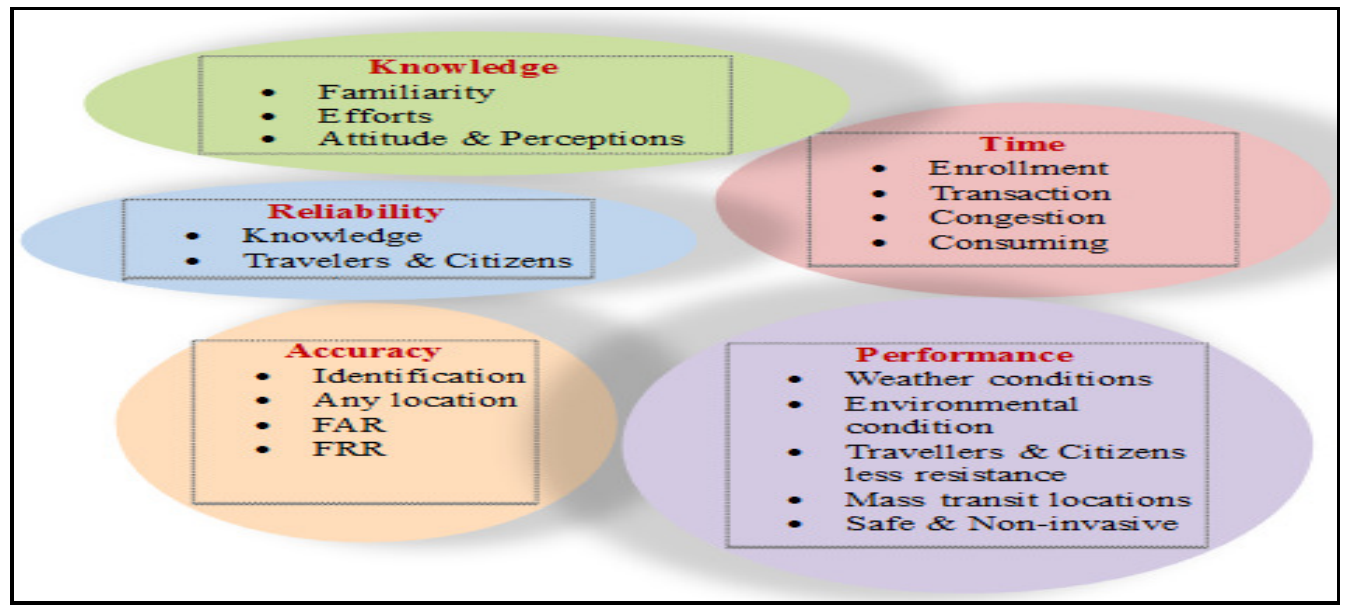

Figure 1: Evaluation Factors of BTMs

\section{Methodology}

The literature was comprehensively reviewed, and the evaluation factors of BTMs were established as it is shown in figure (1). A questionnaire was designed and distributed. Field visits were carried out for almost one month to GDCE and SSBP. The purpose of afield visits is for the following steps:

1. Distribution of questionnaires to the competent departments and sections of the subject matter

2. Conduct meetings with officials to answer some questions related to the thesis and the respondents' answers.
3. Identify the biometric systems used or any other technologies in use.

4. Gather official information and reports related to the thesis subject.

A sample size of 268 employees from the Security Sector of Border Ports (SSBP) of the three border ports of Kuwait; in addition to employees from the General Department of Criminal Evidence (GDCE) were selected. A total of 262 responses were received and analyzed as it is shown in table (2).

Table 2: GDCE and SSBP actual distribution

\begin{tabular}{|c|c|c|c|c|c|c|c|c|}
\hline No & (MOI) & $\begin{array}{c}\text { Distribute } \\
\mathrm{d}\end{array}$ & Missing & Received & $\begin{array}{c}\text { Response } \\
\text { rate }\end{array}$ & Rejected & $\begin{array}{c}\text { Accepted } \\
\text { Accepted } \\
\text { rate }\end{array}$ \\
\hline $\mathbf{1}$ & GDCE & 120 & 1 & 119 & $99 \%$ & 18 & 101 & $84 \%$ \\
\hline $\mathbf{2}$ & Air Port & 115 & 13 & 102 & $89 \%$ & 12 & 90 & $78 \%$ \\
\hline $\mathbf{3}$ & $\begin{array}{c}\text { Al-Abdeli } \\
\text { Land Port }\end{array}$ & 26 & 0 & 26 & $100 \%$ & 7 & 19 & $73 \%$ \\
\hline $\mathbf{4}$ & $\begin{array}{c}\text { Shuwaikh } \\
\text { Sea Port }\end{array}$ & 40 & 7 & 33 & $83 \%$ & 8 & 25 & $63 \%$ \\
\hline $\mathbf{5}$ & $\begin{array}{c}\text { Al-Salmi Land } \\
\text { Port }\end{array}$ & 24 & 5 & 19 & $79 \%$ & 5 & 14 & $58 \%$ \\
\hline $\mathbf{6}$ & $\begin{array}{c}\text { Al-Nowaseeb } \\
\text { Land Port }\end{array}$ & 25 & 6 & 19 & $76 \%$ & 6 & 13 & $52 \%$ \\
\hline \multicolumn{2}{|c|}{ Total } & 350 & 32 & 318 & $91 \%$ & 56 & 262 & $75 \%$ \\
\hline
\end{tabular}




\section{Research Model}

Research model in Figure (2) was developed to explore Kuwait security procedures and BTM used at border ports, problems accrued with the security procedure and BTM, and knowledge familiarity and awareness of the technicians in (GDCE) and the users in
(SSBP) with BTMs concepts. In addition, last investigating and evaluating the effectiveness of BTMs.

familiarity and awareness of the technicians in (GDCE) and the users in (SSBP) with BTMs concepts. In addition, last investigating and evaluating the effectiveness of BTMs.

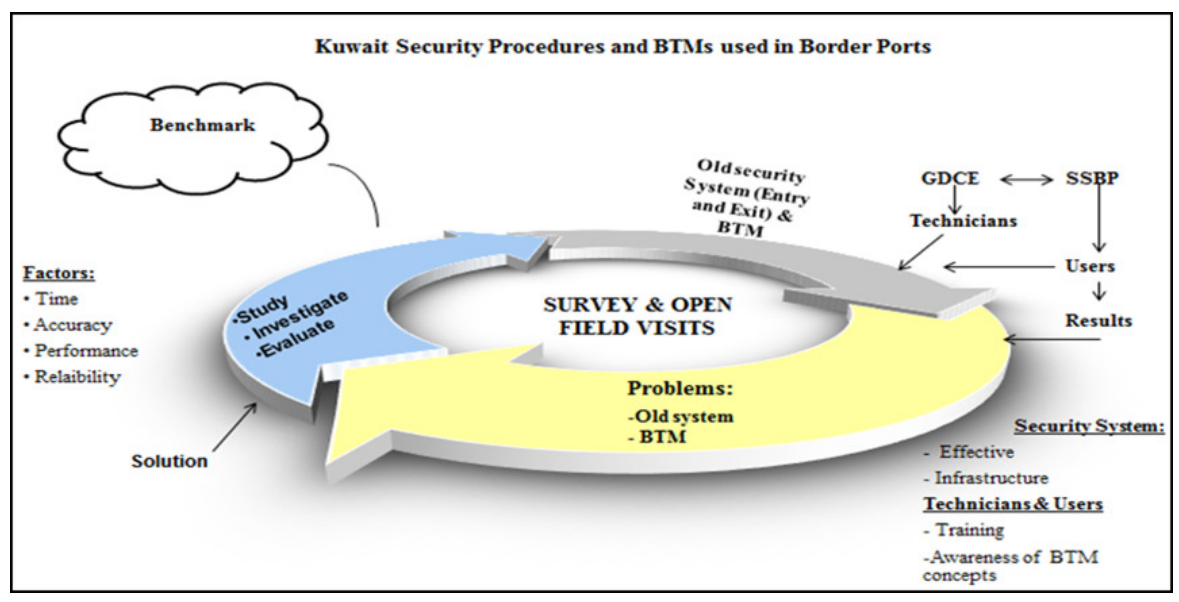

Figure 2: Kuwait Security Procedures and BTM used in Border Ports

\section{Results}

The chapter discusses the results in sequence of these study questions. Furthermore, the variances will be investigated to identify if there are any significant differences by using frequency, chi-square and bar charts in the results between the study sample according to the variables of GDCE and SSBP (three land ports, airport, seaport). In addition, the researcher took the average of the (10) mechanisms, and analysed from an average and above for each question. This is to achieve more accurate results.
Summary of Background, Knowledge, and Familiarity of BTMs for both GDCE and SSBP

The results illustrated in Figure (3) and Figure (4) show that there is a correspondence between GDCE and SSBP on knowledge familiarities of the following BTMs: fingerprint, iris and retinal. Fingerprint comes as the first mechanism by order, but it does not correspond with the following BTMs: facial and signature. 


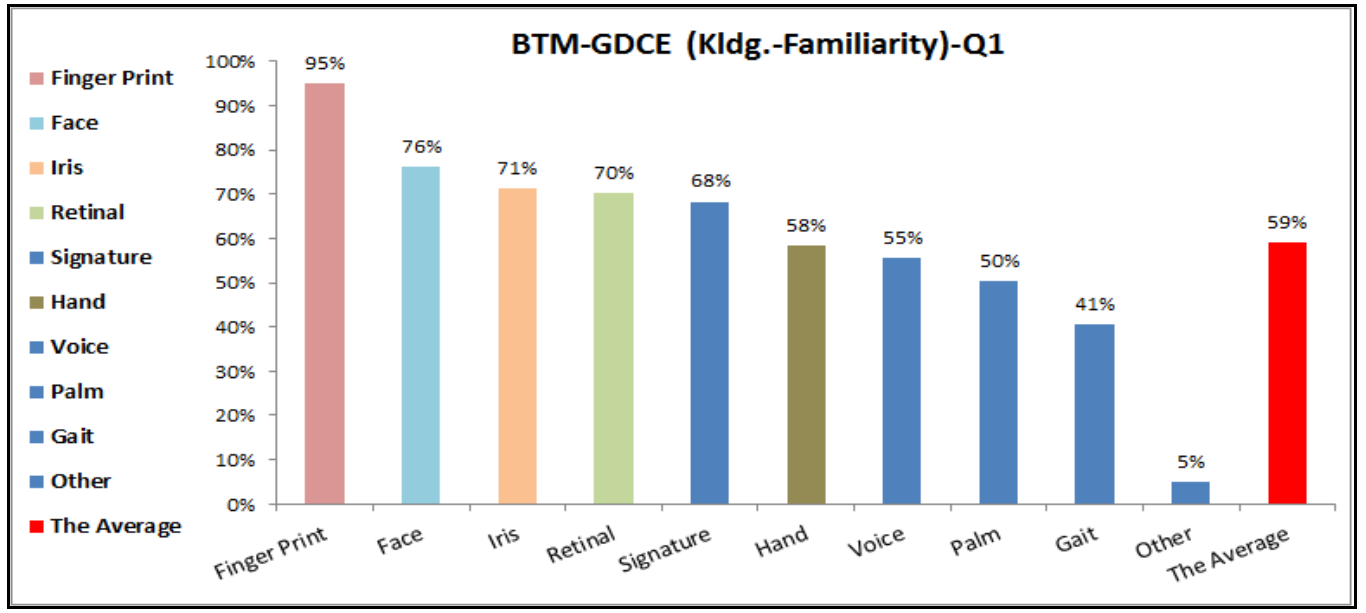

Figure 3: Familiarities with BTM Technologies at GDCE

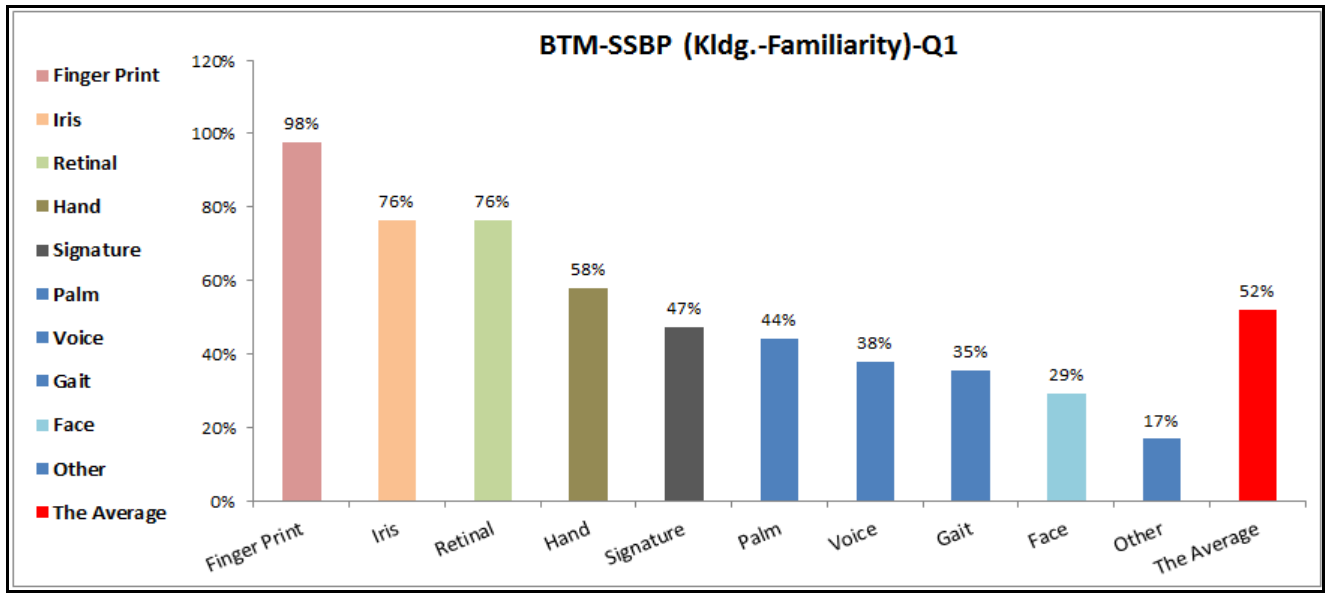

Figure4: Familiarity with BTM Technologies at SSBP

During a field visit to GDCE and SSBP, GDCE has a department of counterfeiting and forgery, which uses a signature mechanism and hand writing to authenticate and to identify a criminal. On the other hand, SSBP does not have a signature mechanism; some individuals (users) in SSBP thought about signature mechanism as it for an attendance instead of using fingerprints, they misunderstood the main purpose of using BTM, which is to authenticate passengers in arrivals and departures.

In a field visit to GDCE, the Personal Identification and Automated Fingerprint Department stated that a facial mechanism is not yet available, while a hand recognition mechanism is available and operational. The hand mechanism takes a photo of the person's face and a scan of his hand. While in a field visit to SSBP, officials stated that hand recognition is not operational in land ports and seaports yet, even though they have the devices. The reason for this according to officials in both ports is that GDCE has not trained the users about how to operate such a device yet. Moreover, in order to operate these devices, there must be a network connection, which is not available at that moment.

Compared to the results in Figure (5) and Figure (6), they show that there is coordination between GDCE and SSBP, 
especially at the Airport where fingerprint $\quad$ BTM is mostly used.

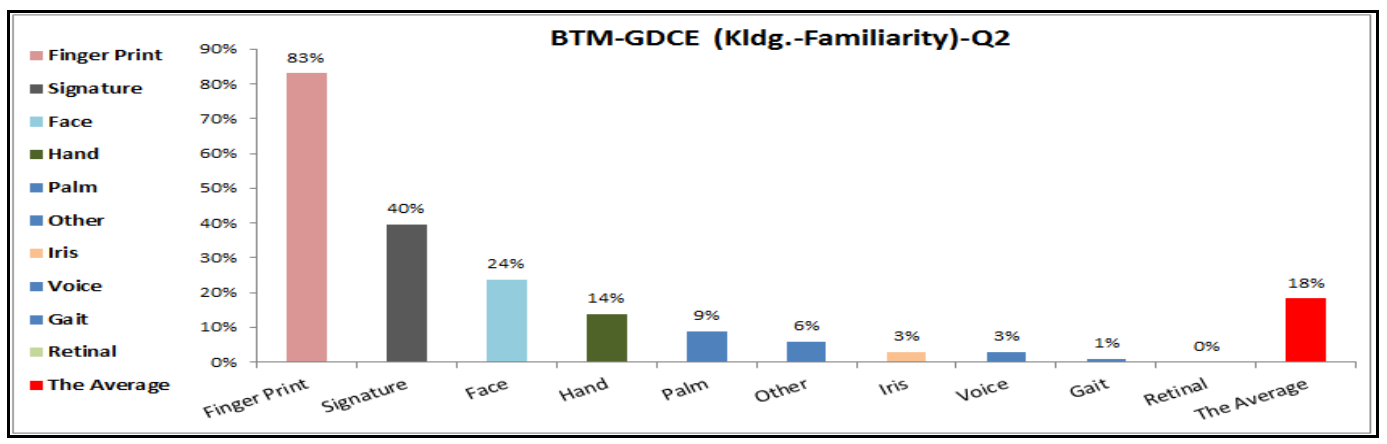

Figure 5: The BTM used before at GDCE

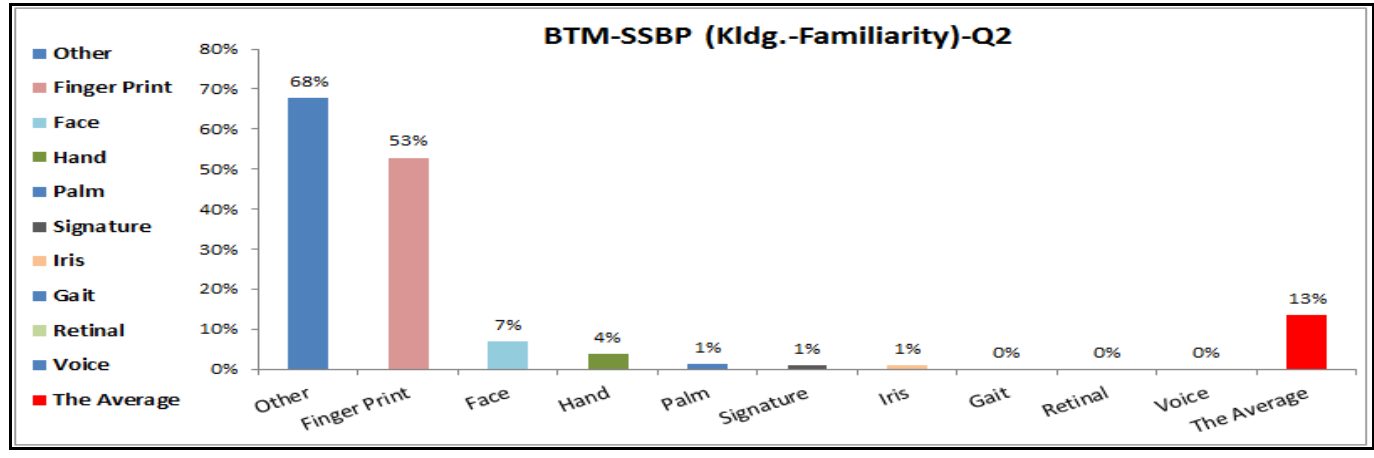

Figure 6 : The BTM used before at SSBP

The Head Office of Automated Fingerprinting in GDCE stated during the field visits that, the hand recognition mechanism is available and operational. This mechanism takes a photo of the person's face and scans his hand. The facial mechanism as an automated recognition system is not available to them yet. On the other hand, they do use manual facial mechanisms in forensic applications with cadavers when the face is not recognizable. This procedure is done to identify or recognize facial features through other measures, which can be gotten from the skull. This is why some technicians regard the facial mechanism as still applicable in such cases.

There is a correspondence between GDCE and SSBP. The rate of $77 \%$ from the individuals in GDCE in agreement that BTM is effective in job performance, while $89 \%$ from the individuals in SSBP are in agreement that BTM has an effective job performance; while $55 \%$ of the individuals at border ports strongly agree that BTM is effective in job performance.

\section{Identification of Methods and Technologies Used in Kuwait}

The results in Figure (7) and Figure (8) show that GDCE and SSBP are still using the same mechanisms and no other new BTMs have been introduced yet. The GDCE mostly still uses fingerprinting 88\%, and SSBP is mostly still using Entry and Exit security system. 69\% of individuals' responses from SSBP show that Entry and Exit security system is mostly used in departures and arrivals for authentication in land ports and seaport, while users in the Airport use fingerprint, which is the only BTM operational in departures and arrivals' counters at Kuwait Airport. 


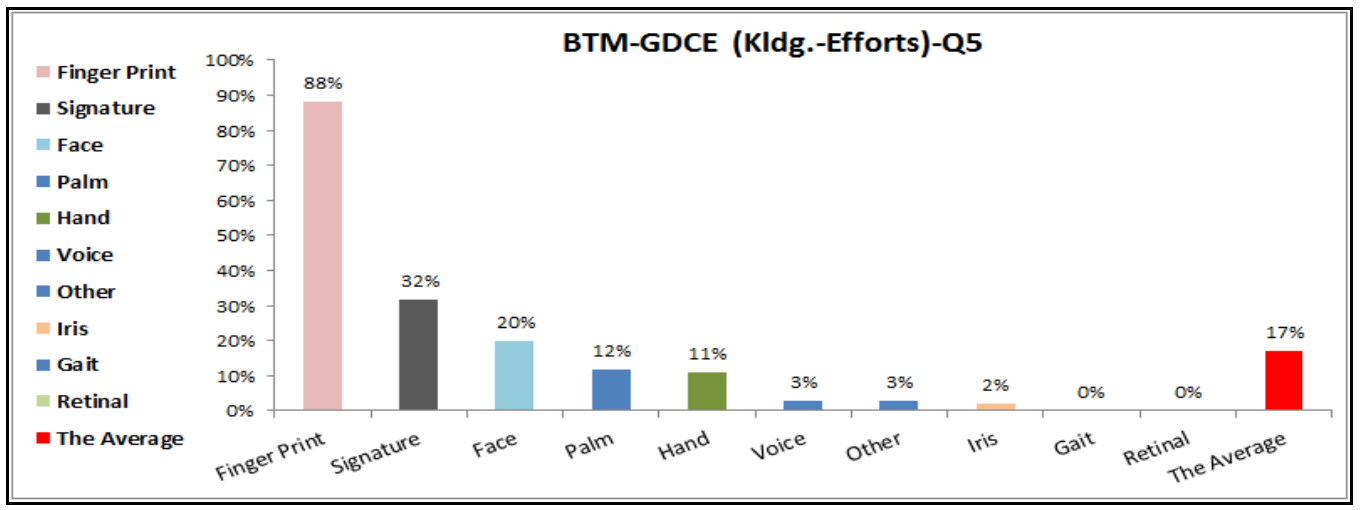

Figure 7: The BTM that still applying at GDCE

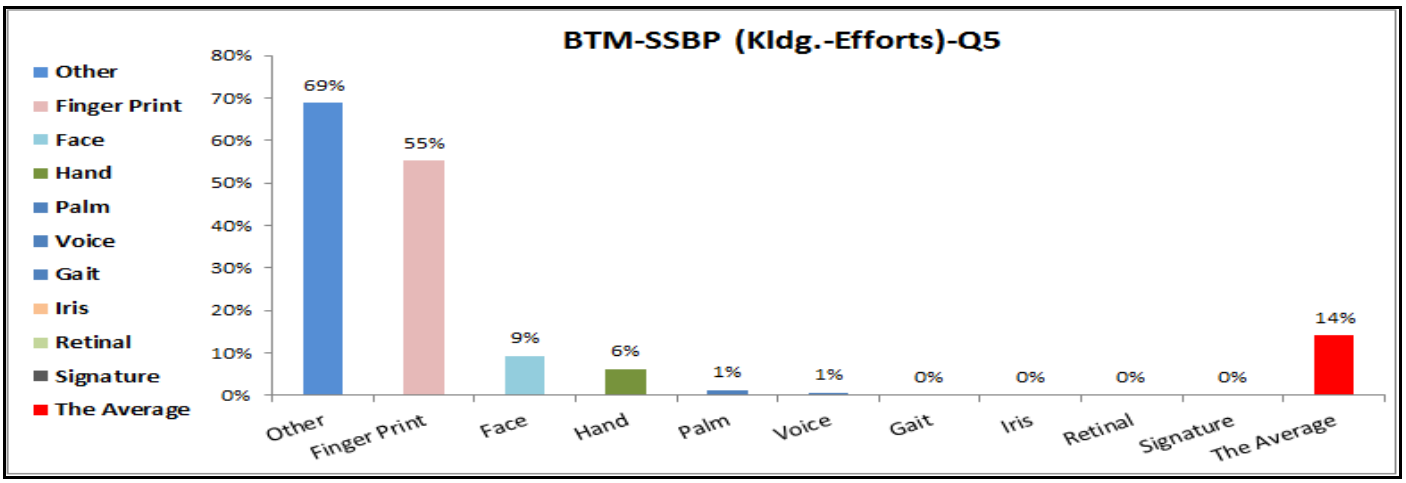

Figure 8: The BTM that still applying at SSBP

Some users at Airport considered facial mechanism is still applied. On the other hand, according to a field visit, facial mechanism as an automated BTM does not exist yet. The respondents (users) employ the facial mechanism manually, especially for women. In the case where some women passengers cover their faces with a veil, the employee at the counter (user) has to match with the facial image with that of the passport. This manual procedure for facial recognition, which is called Al-Tatbeeq, has made some users to choose the facial mechanism as a BTM for authentication.

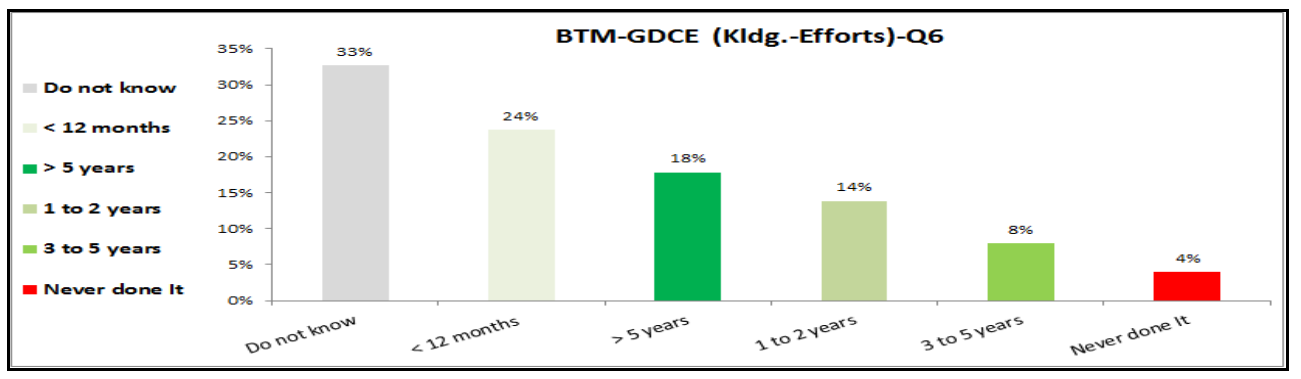

Figure 9: Last time applied the use of BTM in GDCE

Adel Ismail Al-Alawi, Raeed Khalid E. Al-Faresi and Refaat Hassan Abdel-Razek (2016), Journal of e-Government Studies and Best Practices, DOI: 10.5171/2016. 542264 


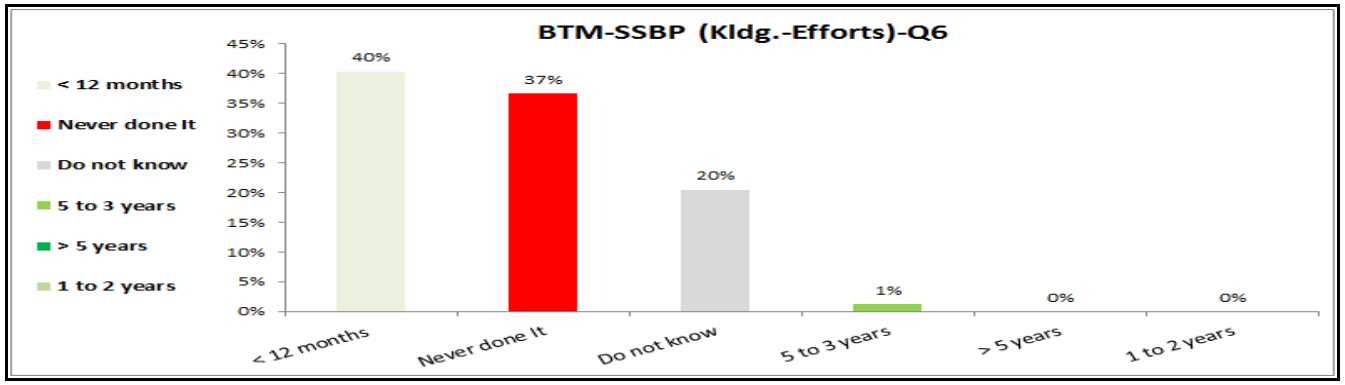

Figure 10: Last time applied the use of BTM in SSBP

The rate of $24 \%$ in Figure (9) shows the individuals' responses in GDCE indicated that BTM has been applied for less than twelve months, while Figure (10) shows that $40 \%$ of the individuals' responses in SSBP indicated that BTM has been applied for less than twelve months. This indicates that BTM was newly introduced and applied at Kuwait Airport. On the other hand, $37 \%$ of the individuals' responses in SSBP indicated that it has never been done at most of land ports and seaport. In addition, $20 \%$ of the individuals' responses indicated that they did not know was when the last time they applied the use of BTM. The researcher indicated their answers to their thinking of GDCE's work procedures in each port, and they do not know when GDCE which is applied BTM and not as an automated system. There appeared to be a correlation between GDCE and SSBP on when the last time the use of BTM was applied, which in both cases was less than twelve months. During a field visit on August 6, 2011 regarding the last time applied fingerprinting was done at the Airport in the arrivals hall, officials said that they started using the fingerprint mechanism for almost three months.

Efforts toward BTMs from GDCE and SSBP

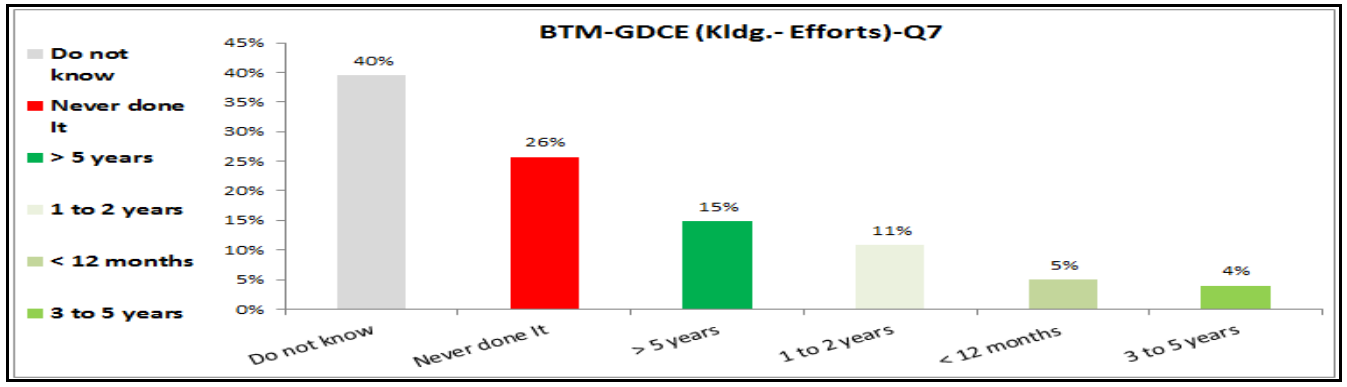

Figure 11: Last time conducted concept of BTM at GDCE

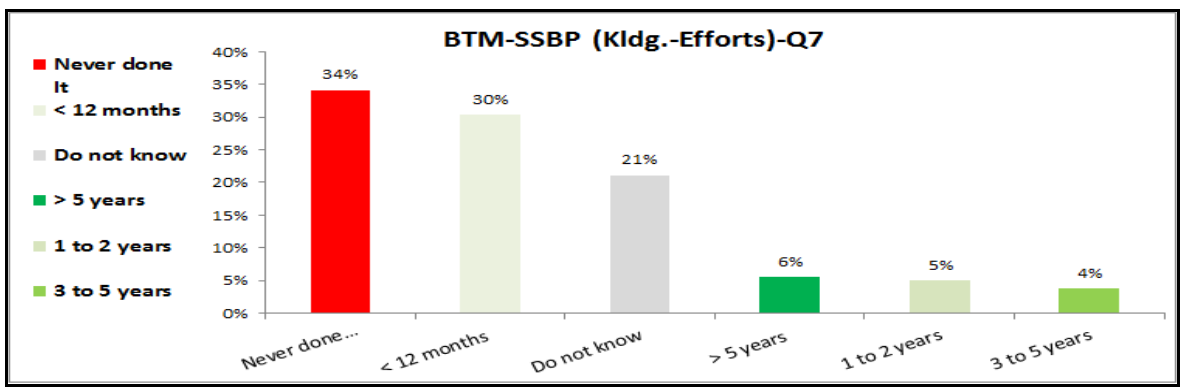

Figure 12: Last time conducted concept of BTM at SSBP

Adel Ismail Al-Alawi, Raeed Khalid E. Al-Faresi and Refaat Hassan Abdel-Razek (2016), Journal of e-Government Studies and Best Practices, DOI: 10.5171/2016. 542264 
The results in Figure (11) show that $26 \%$ of the individuals' responses in GDCE indicated that BTM concepts were never been introduced or utilized. This indicated that individuals in the GDCE is not in following (Updating) with newly BTM the same as in the SSBP, while Figure (12) shows that $34 \%$ of the individuals' responses indicated that BTM concepts have never been introduced, while 30\% indicated this was true in the time less than 12 months ago. This reflects the lack of training courses given by GDCE and SSBP during a few and intermittent periods.

\section{Attitude and Expectations of GDCE's Technicians and SSBP's Users toward BTMs}

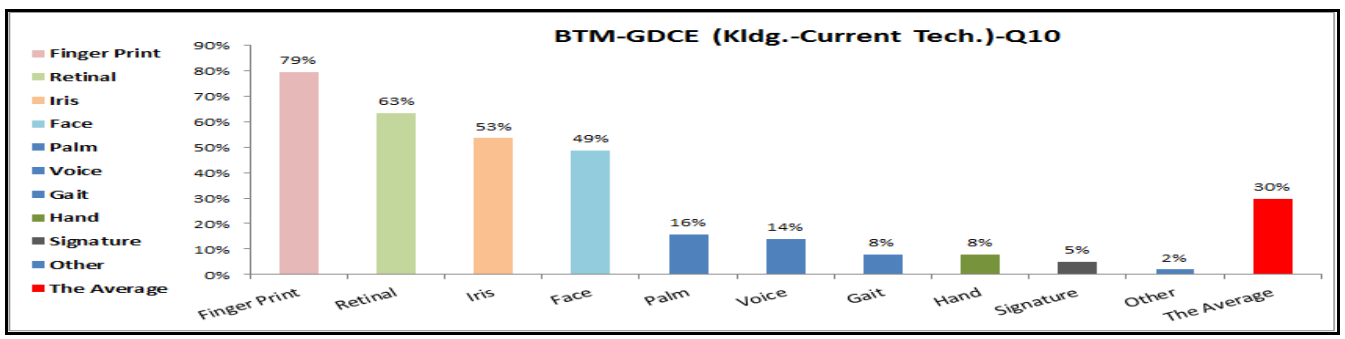

Figure 13: Better BTM to use for controlling border ports for GDCE

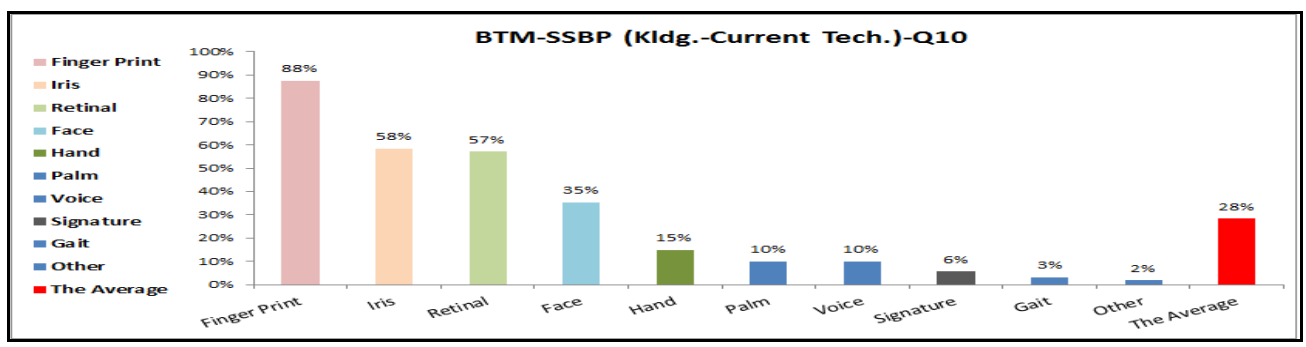

Figure 14: Better BTM to use for controlling border ports for SSBP

According to the results shown in Figure (13) and Figure (14), the results are compatible results between GDCE and SSBP on the fact that it is better BTM for controlling border ports in Kuwait: these BTMs include fingerprint, iris, retinal and facial. In addition, the results from Figure (13) and Figure (14) show that there is congruence among the respondents from the GDCE and the SSBP as to which is the best BTM to use. These are fingerprint, iris, retinal and facial, but they are dissimilar in their first preference of BTM. 


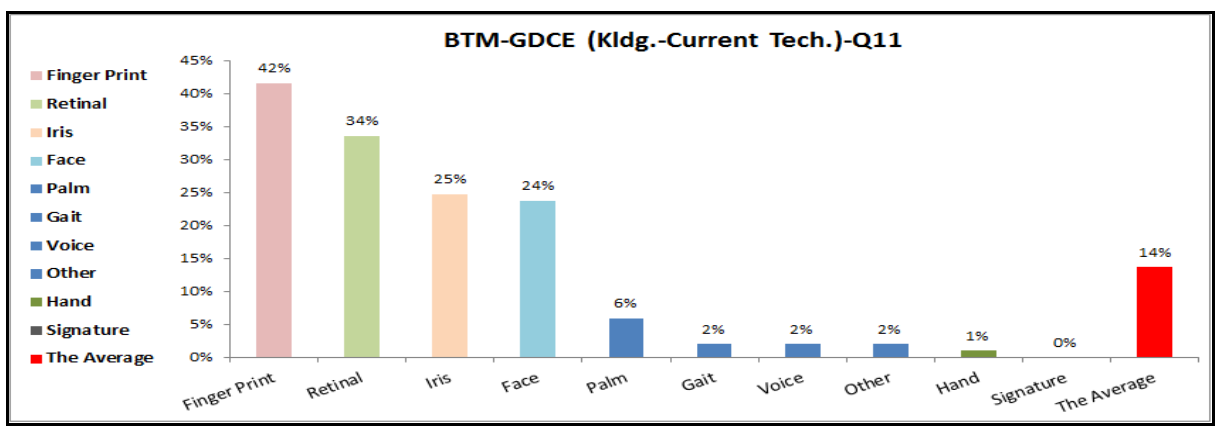

Figure 15: The best BTM to use for controlling border ports for GDCE

Figure (15) showed that $42 \%$ of respondents from the GDCE consider fingerprinting as the best BTM to use for controlling border ports. The researcher believes this response from the GDCE came about for several reasons. First of all from an interview in Al-Rai newspaper (11672) on June $6^{\text {th }}, 2011$, the Manager of the Personal Identification and Automated Fingerprint department spoke about the existence of integrated archive of which features approximately 6.5 million fingerprints of citizens and residents, in addition to that of 600 thousand of criminal files. Secondly, the fingerprint mechanism is an easy application to use, and has been in practice since the GDCE first existed in Kuwait. This should give GDCE more knowledge when dealing with such mechanism more than any other BTM. According to the researcher in light of the above, this created the concentrated focus on fingerprinting at the GDCE.

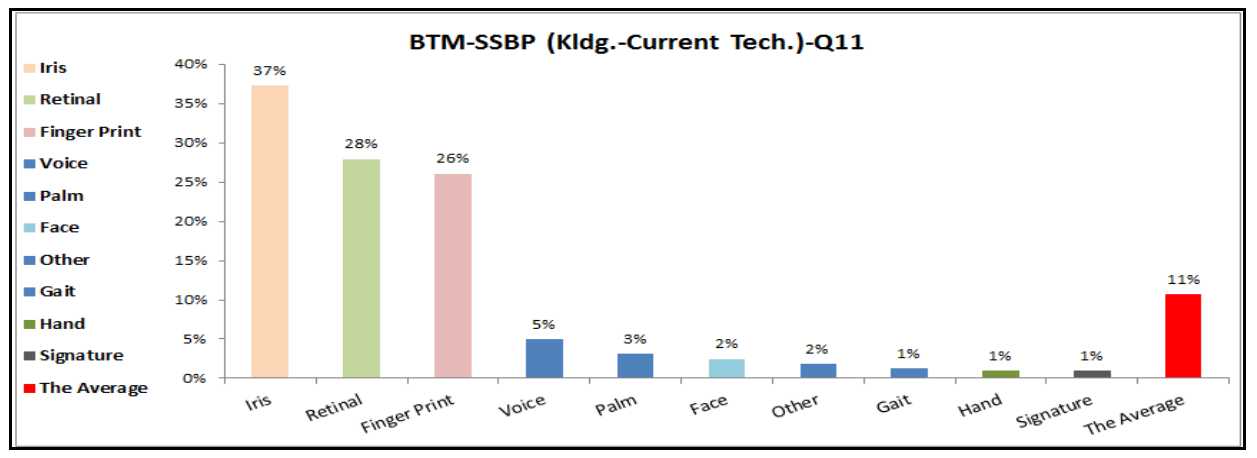

Figure 16: The best BTM to use for controlling border ports for SSBP

On the other hand, Figure (16) shows that in SSBP, $37 \%$ of the respondents considered iris recognition technology as the best BTM to use for controlling border ports. This reflects the reflection of the use of iris recognition in (UAE). During a field visit to the SSBP, it was revealed that most of the users and technicians considered UAE more developed in obtaining and using modern technology especially those used securities 


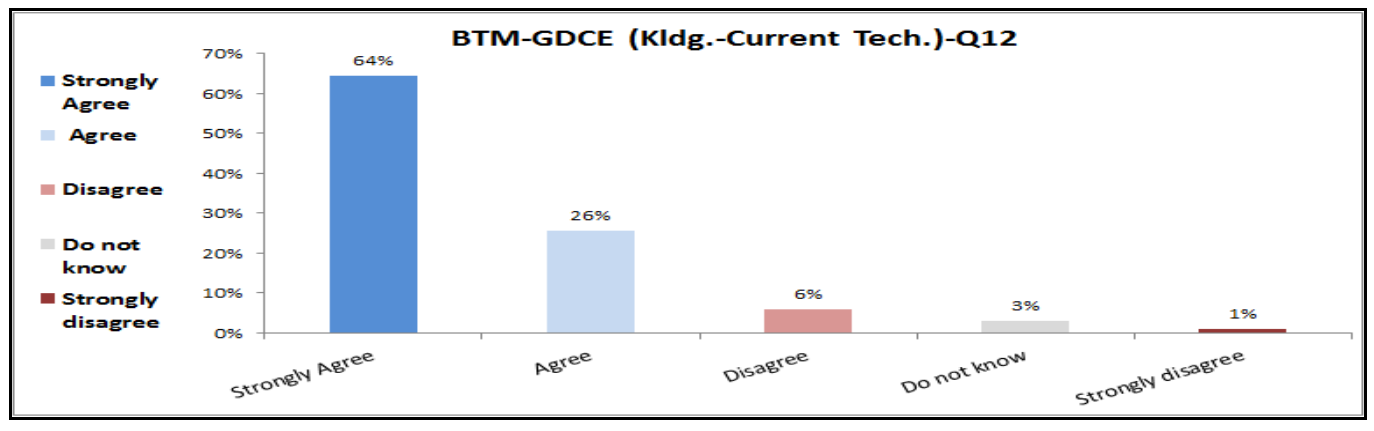

Figure 17: Does BTM increase security and highly recommended for GDCE

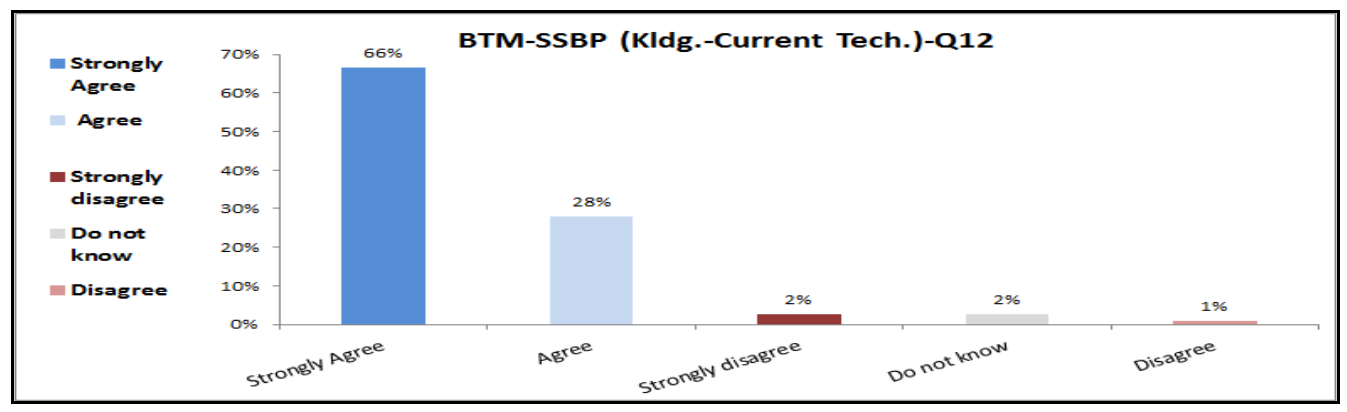

Figure 18: Does BTM increase security and highly recommended for SSBP

The results from Figure (17) and Figure (18) show that there is compatibility of agreement between GDCE and SSBP in which both agree that BTM is highly recommended to use in border ports, and that it will increase security. Moreover, the rate of $90 \%$ from the individuals in GDCE is in agreement that BTM is highly recommended to use in controlling border ports, while the rate of $94 \%$ from the individuals in SSBP is in agreement that BTM is highly recommended to use in controlling border ports. Thus, this means that BTM is more often highly recommended from the individuals in SSBP than individuals in GDCE, and highly recommended from both of them.
During a field visit to land ports and seaports, individuals (users) highly recommended the application of BTM for other reasons; such as to develop a management security system, which assists in resolving direct enquiries expeditiously for any situation regarding the passengers in entering and exiting the country. Thus with current technology, GDCE must be contacted and waiting time for a response from thirty minutes to one hour. As of the current technology (other), individuals (users) face several circumstances where in the case of any mistake in their job performance they often face administration investigations and financial penalties. 


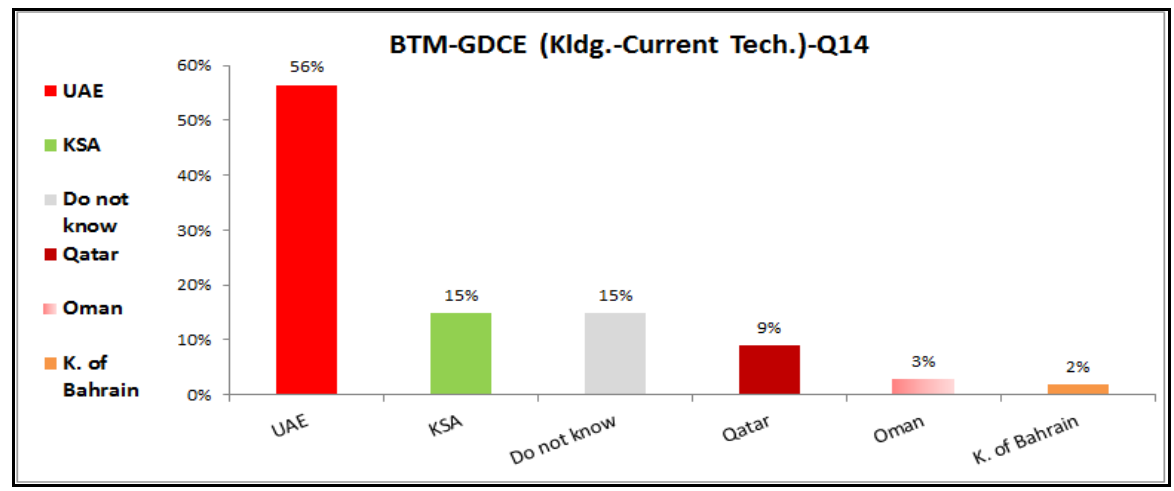

Figure 19: GCC benchmark in controlling border ports using BTM for GDCE

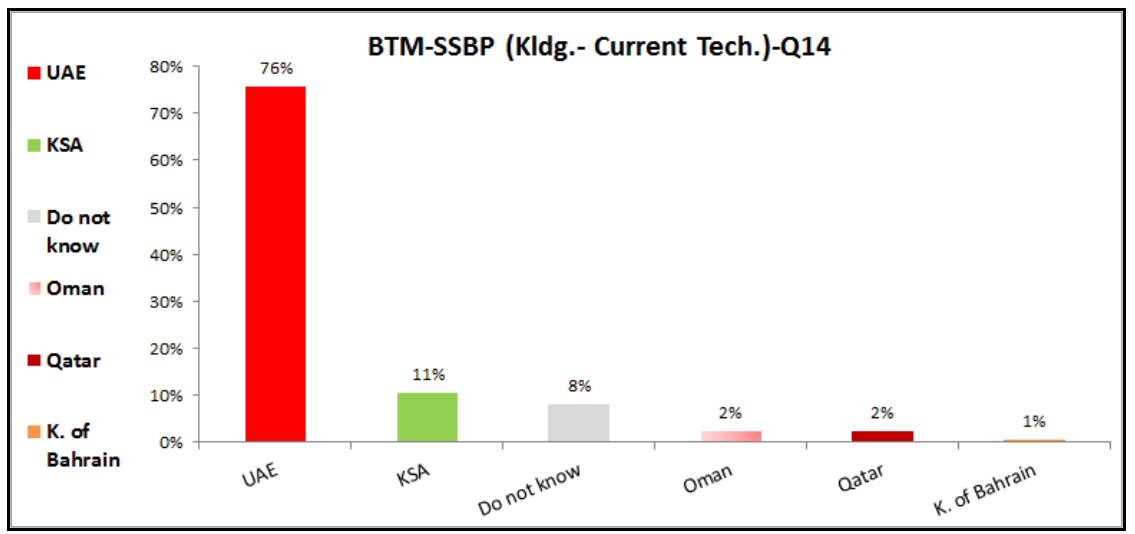

Figure 20: GCC benchmark in controlling border ports using BTM for SSBP

Therefore, the results from Figure (19) and Figure (20) show that there is a correspondence between GDCE and SSBP in the consideration of the border control procedures in the UAE as a benchmark in controlling border ports using BTM. The results regarding this point from the SSBP is that $76 \%$ agree while only $56 \%$ of those from the GDCE believed that the UAE should be considered as benchmark Moreover, those respondents from the
SSBP highly recommended using iris recognition for controlling border ports to increase security. This recommendation could be correlated with response regarding the UAE benchmark for using iris recognition in its border ports, and came with amazing results after applying iris (AlRaisi and Al-Khouri, 2008), which means the recommendation of SSBP is compatible with the previous study. 
Summary of the Time Factor Results

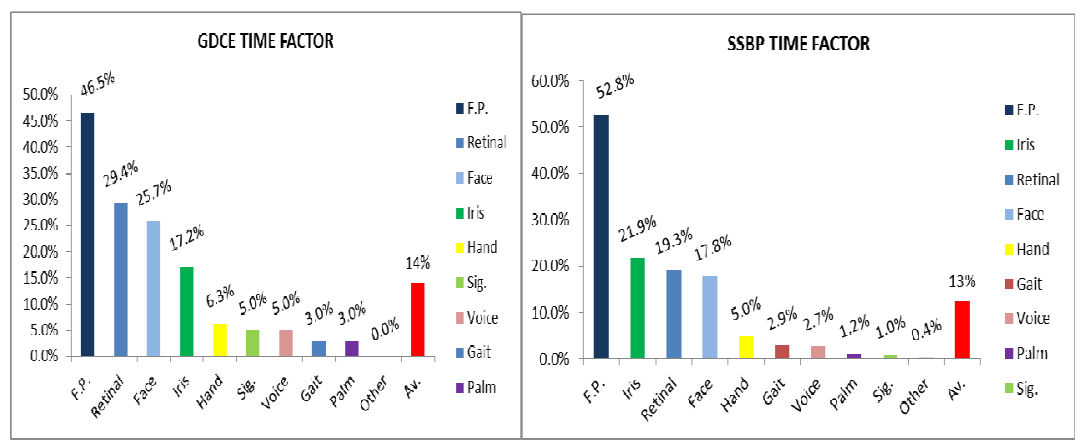

Figure 21: Time factor of BTMs for GDCE and SSBP

The results from Figure (21) show that there is agreement between GDCE and SSBP regarding BTMs time factor. GDCE and SSBP first's preference is fingerprinting, but they differ in their other BTMs preferences. The GDCE considers retinal $(29.4 \%)$ as their second choice, facial $(25.7 \%)$ as their third choice and iris $(17.2 \%)$ as their fourth choice, while respondents from the SSBP chose iris $(21.9 \%)$ as their second choice, retinal $(19.3 \%)$ as their third choice and facial as (17.8\%) their fourth choice.

\section{Summary of the Performance Factor Results}

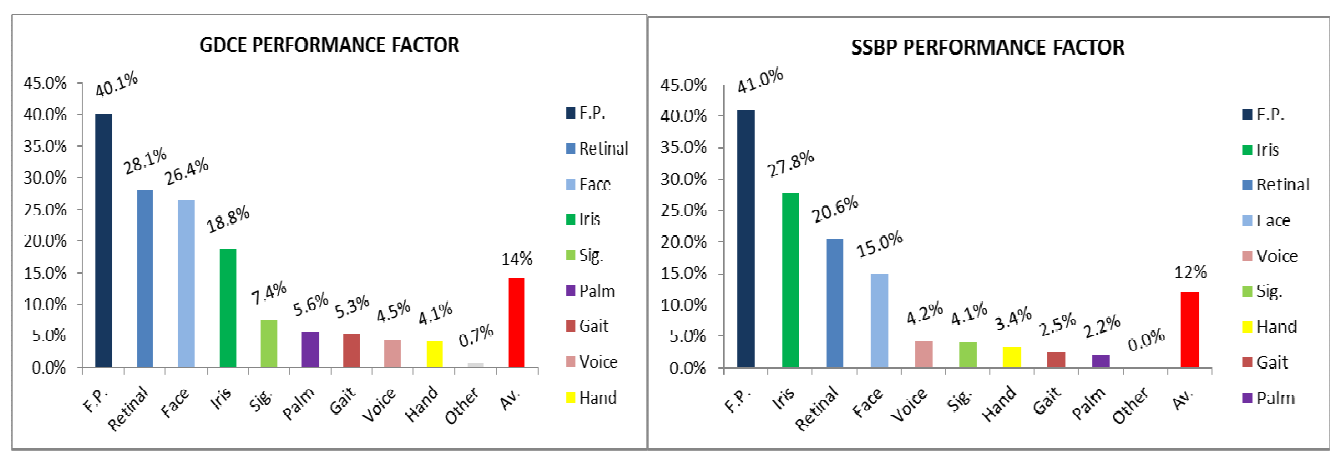

Figure 22: Performance factor of BTMs for GDCE and SSBP

The results in Figure (22) show that there is correlation between the GDCE and the SSBP on the best BTM performance. Fingerprint considers yet the first mechanism in both the GDCE and SSBP, but they do not correspond with the other BTM preferences. After fingerprint mechanism, the GDCE prefers retinal by $(28.1 \%)$, facial by $(26.4 \%)$ and iris by $(18.8 \%)$. Thus, the SSBP preference after fingerprinting is iris (27.8\%), retinal by $(20.6 \%)$ and facial by (15\%). In stating Dillingham (2002) cited in Al-Raisi and Al-Khouri (2008) and Robert (2005), one of the disadvantages of fingerprinting, iris, facial, and retinal recognition is that poor environmental conditions can adversely affect collection sample from any individual including passengers. The acceptance of different varieties of BTMs comes from citizens or visitors to a country. There are various criticisms or objections regarding the use of BTM. Fingerprint is associated with law enforcement and there exists hygiene 
concerns from both citizens and visitors when having their fingerprints taken because of the direct contact between them and the device.

These studies emphasized that user resistance against having iris scanned from passengers who wish to enter the UAE, and that is why a law enacted in the UAE for mandatory iris recognition scanning for foreigners and criminals. For the retinal mechanism, there is concern regarding the actual rays that scan retina, and additionally, some think that it is too invasive. Furthermore, there is a concern regarding facial recognition mechanism from authorities that some criminals or expelled individuals might be able to defy the system by altering their faces through plastic surgery.

\section{Summary Results of Accuracy Factor}

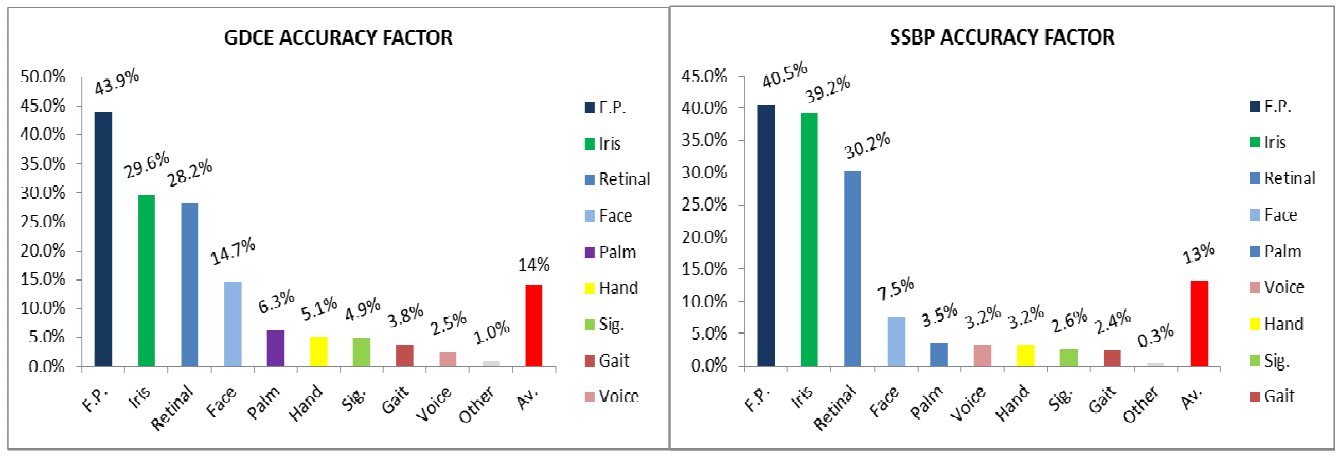

Figure 23: Accuracy factor of BTMs for GDCE and SSBP

The results in Figure (23) show that the GDCE and the SSBP are compatible in three BTMs (fingerprint, iris and retinal) as the most accurate BTMs. The GDCE considers fingerprints at $43.9 \%$ and it thus ranked first, whereas iris recognition at $29.6 \%$ ranked second, and retinal at $28.2 \%$ ranked third. Furthermore, the SSBP considers fingerprints at $40.5 \%$ and it thus ranked first, whereas iris recognition at $39.2 \%$ ranked second, and retinal at $30.2 \%$ ranked third.

During a field visit to Kuwait Airport, and the survey questions about how accurate fingerprinting is, most of the users indicated that fingerprinting is accurate but in some cases, they could not give accurate results. For example, some foreign passengers intentionally burn their Index finger in order to sneak in. In such a case, they have to take the passenger to the GDCE for re-examination and identification. Another case is when people employed as construction workers or mechanics usually have calloused fingers; it is difficult for the fingerprint mechanism to identify and verify the passenger. In such cases, the user has to ask the passenger to wet their finger with some moisturizing cream to soften the skin on the thumb. One of the major problems facing the users and fingerprint mechanism is the updating of information, which is GDCE's responsibility.

According to Poli et al, (2009), matching high quality fingerprints with small intrasubject variations is not difficult. Moreover, every reasonable algorithm can do this with high accuracy. The challenge is when matching samples of poor quality which may have been affected by a large displacement and/or rotation, or a nonlinear mutilation, or thirdly, different pressure, skin condition and lastly, feature extraction errors.

In addition, according to the users in the Airport, some passengers who used to have criminal records and have solved their problems before they left the country for a couple of months have difficulty when they come back, and they are surprised that the fingerprint system will not allow them to pass FRR. On the other hand, other passengers who have committed a crime 
and left the country return and then pass through to re-enter or leave the country (FAR) because of sluggish updating. Moreover, sometimes the network itself is slow and this could affect the effectiveness of the performance. According to previous studies, fingerprinting matches challenged by database size, adding time to matches or necessitating filtering as a search acceleration technique. With this challenge, network connections must always be operating, and maintenance must periodically have been done.

Al-Rai (2011) newspaper (11672) on June 16 stated that the Manager of the Personal Identification and Automated Fingerprint Department, Colonel (Dr.) Hamid Al-Khalidi said, we were able to stop (377) expellees who tried to seek re-entry after two months of the instillation of the fingerprint BTM. Al-Raisi and Al-Khouri (2008) stated that in the UAE, fifty people were caught in less than three months after the instillation of iris recognition system. At the time of Al-Raisi and Al-Khouri (2008) study, they stated that 56,484 persons have so far been found on the watch list and were seeking re-entry. The number of searches is expected to rise frequently in the next few months at that time as the government is currently studying to include more traveler categories to be eligible for iris security system at all UAE border entry points.

Galbally et al (2012) stated that materials with fake fingers are produced such as gelatin or silicone which create of fake fingerprints whether deliberately or not deliberately done by the individual with and without the cooperation of the user. The high performance shown by the proposed system correctly classifies almost $90 \%$ of the fingerprint images, proves its ability to adapt to all types of direct attacks through its efficiency as a method to minimize their effect and enhance security capability of fingerprint verification systems. On the other hand; liveness detection for iris recognition is based on the quality of measures which also has been presented. Liveness detection was tested based on iris database which includes 1,600 real and fake images, where it reached a total $100 \%$ of correctly classified (real or fake) samples, proving that this method has a high potential called (anti-measure) to prevent direct attacks to the sensor.

\section{Summary of the Reliability Factor Results}

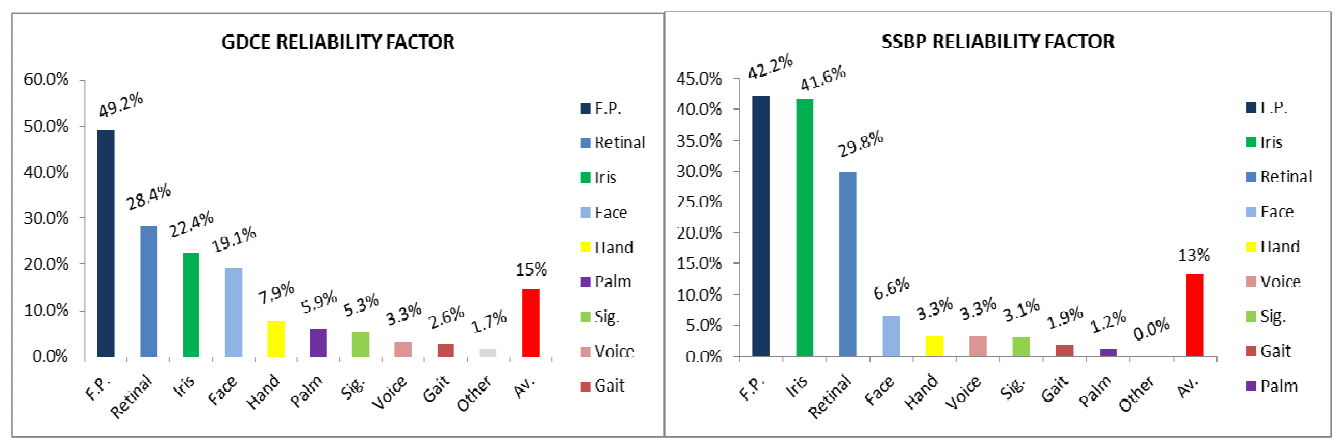

Figure 24: Accuracy factor of BTMs for GDCE and SSBP

The results in Figure (24) show that the GDCE and the SSBP are compatible about which three BTMs that is more reliable in performing at any time or any place, and can be used in different environmental conditions. In addition, they are compatible with the belief that the fingerprint mechanism is more reliable and thus it ranked first. On the other hand, the GDCE and the SSBP do not correspond to the rank of the other BTMs. The GDCE considers retinal mechanism to be more reliable after fingerprint by $28.4 \%$ and become second, iris recognition become in the third place by $22.4 \%$ and facial mechanism in the fourth place by $19.1 \%$. The SSBP has a different opinion regarding their preferences on BTM ranking. The SSBP 
considers the iris recognition mechanism as more reliable after fingerprints, which ranked second with an approval rate of $41.6 \%$, while retinal mechanism ranked third with an approval rate of $29.8 \%$.

The results also show that GDCE and SSBP have chosen fingerprints as the best mechanism than the current one, which has been used. This means that even though land ports and seaport preferred iris recognition as the best BTM compared to their current existing one for the exit and entry security system (other), the SSBP preferred fingerprints as the best mechanism at $42.2 \%$. This preference may have come about because the Airport uses fingerprints in their exit and entry security system, and they find fingerprinting convenient and are comfortable with it. The SSBP prefers iris recognition after fingerprints and it ranked second with a close approval rate to that of fingerprinting at $41.6 \%$.

On the other hand, in the GDCE, the manager of the Personal Identification and Automated Fingerprint Department Colonel (Dr.) Hamid Al-Khalidi announced in the Al-Rai newspaper on June $14^{\text {th }}$, 2011, (11672) a plan to implement the iris recognition in all border ports. His announcement is compatible with the SSBP first preferences of iris recognition and the UAE experience.

\section{Accumulating Results of GDCE Responds}

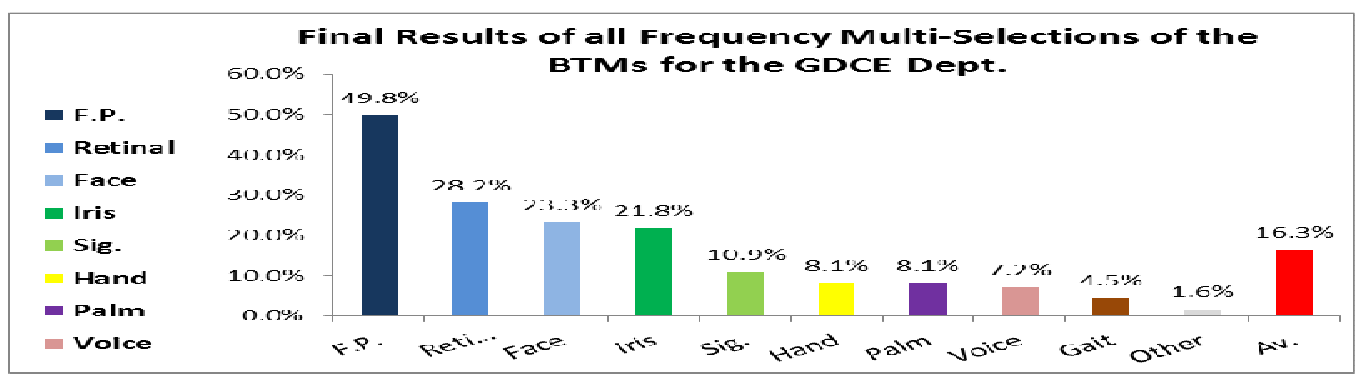

Figure 25: All factors of BTMs for GDCE

Depending on the average of the BTMs for GDCE, which is $16.3 \%$, the results in Figure (25) show accumulating results of BTMs that are above the average as follow: fingerprint by $49.8 \%$, retinal $28.2 \%$, facial $23.3 \%$ and iris $21.8 \%$.

\section{Accumulating Results of SSBP Responds}

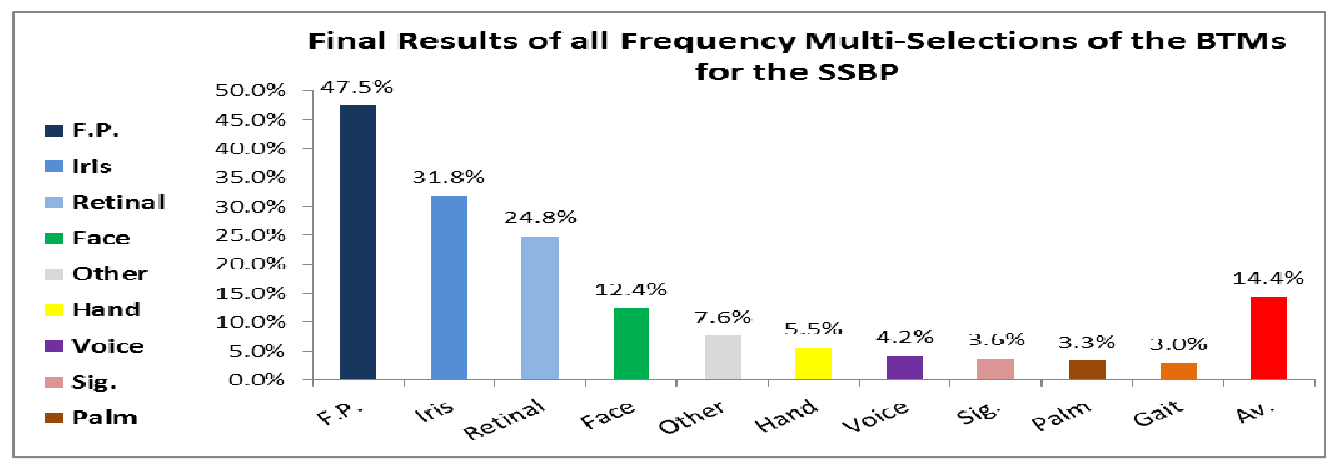

Figure 26: All factors of BTMs for SSBP 
Depending on the average of the BTMs for SSBP which is $14.4 \%$, the results in Figure (26) show accumulating results of BTMs that are above the average as follow: fingerprint by $47.5 \%$, iris $31.8 \%$ and finally retinal $24.8 \%$.

\section{The Final Accumulating Results for GDCE and SSBP Responds}

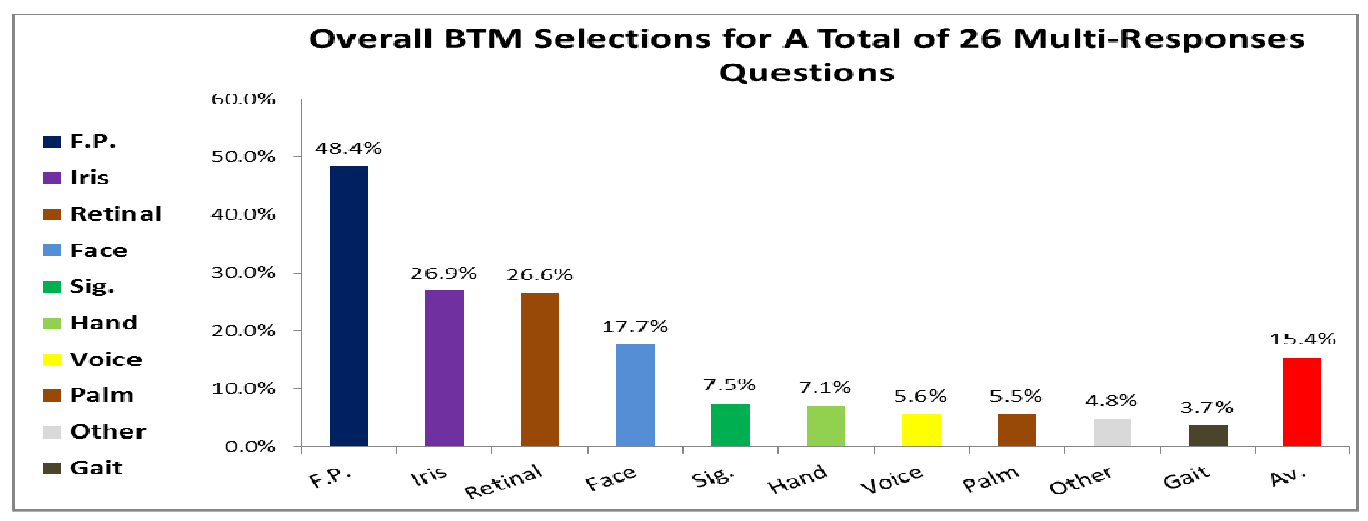

Figure 27: Factors of BTMs for GDCE and SSBP

Based on the average of the BTMs for GDCE and SSBP which is $15.4 \%$, the results in Figure 27 show the accumulating results of BTMs that are above the average as follow: fingerprint $48.4 \%$, iris $26.9 \%$, retinal $26.6 \%$, and finally facial $17.7 \%$.

\section{Conclusions}

According to the objective of the study, and the analysis of the results, regarding the identification and the evaluation of BTMs in order to improve immigration, population surveillance and pre-emption in the border ports of the State of Kuwait, to insure and reach high security level for the country.

In the general evaluation, the results showed that BTMs are highly demanded and recommended from GDCE and SSBP to use in Kuwait for controlling border ports. The results also showed that GDCE and SSBP strongly agreed that BTM is effective in job performance. The individuals in GDCE expressed that the fingerprint was the most effective mechanism and the best in controlling border ports; while the individuals in SSBP selected iris recognition.
While in the evaluation of knowledge familiarity of BTMs, the results showed that some of the individuals in the GDCE and SSBP had a lack of knowledge regarding BTMs' concepts such as facial mechanism. This is due to inadequate training courses which were given during a few and intermittent periods.

The identification of methods and technologies used in Kuwait, the results showed that the current security technologies in SSBP were the traditional entry and exit security system, fraud passport detector, and fingerprint mechanism. Kuwait International Airport used the three mentioned technologies, while the land ports and seaport used the traditional entry and exit security system only. The results revealed that fingerprint mechanism is newly introduced at Kuwait International Airport. The use of fingerprint mechanism decreased the number of illegal entry from expellees who tried to re-enter the country. The GDCE and SSBP are able to match individuals seeking re-entry to the country with the current technologies. The results showed that with the current technologies, there is still a chance for some individuals to penetrate the system. 
The time factor evaluation of BTMs, the results showed that both GDCE and SSBP considered that the BTMs were effective concerning the enrolment time. The comparison between BTMs regarding time factor indicated that the most effective mechanism in enrolment time was the fingerprint. The results also showed that GDCE preferred fingerprint then facial recognition, while SSBP preferred iris recognition after fingerprint. Regarding congestion time and time consuming; GDCE preference was fingerprint then retinal; while SSBP preference was fingerprint then iris.

Regarding BTMs response time for mass transit locations, GDCE and SSBP considered fingerprint the best. GDCE preferred retinal after fingerprint; while SSBP preferred iris recognition after fingerprint.

In the evaluation of BTMs performance, the results revealed that both GDCE and SSBP considered fingerprint mechanism the best BTM among the other BTMs in terms of performance in different weather conditions. After fingerprint mechanism, GDCE preferred facial, retinal and iris respectively.

The results also revealed that both GDC and SSBP agreed that fingerprint mechanism is the most reliable in performance in different environment conditions. The results showed that GDCE and SSBP considered fingerprint mechanism, iris and retinal reliable BTMs in performance at any time any place, and can be used in different environmental conditions.

The results revealed that both GDCE and SSBP agreed that fingerprint mechanism has less resistance from visitors and citizens. GDCE considered retinal mechanism as the second BTM, which has less resistance from visitors and citizens; while SSBP second preference was iris recognition, and the third preference for both GDCE and SSBP was the facial.

The results showed that GDCE considered facial mechanism the most safe and noninvasive mechanism; while SSBP considered iris recognition the most safe and non-invasive mechanism.

In the evaluation of BTMs accuracy, GDCE considered fingerprint mechanism better regarding FRR then iris recognition; while SSBP had a different opinion where fingerprint came after iris recognition regarding FRR. The results showed correspondence between GDCE and SSBP on BTMs which have better FAR results and in their order too. These BTMs were fingerprint, iris recognition and retinal.

GDCE considered fingerprint mechanism superior in accuracy among other BTMs then iris recognition and retinal, while SSBP considered iris recognition superior in accuracy among other BTMs then come the retinal with the fingerprint.

Moreover, the results showed that both GDCE and SSBP agreed that fingerprint mechanism helped avoid duplicate identification.

While in the evaluation of BTMs reliability, GDCE considered facial, retinal, and iris more reliable BTMs after fingerprint respectively; while SSBP considered iris recognition, retinal and facial more reliable BTMs after fingerprint respectively.

\section{References}

1. Al-Raisi, A and Al-Khouri, A. (2008). Iris recognition and the challenge of homeland and border control security in UAE. Journal of Telematics and Informatic, 25(2): 117-132.

2. Amoore, L. (2006). Biometric borders: Governing mobilities in the war on terror. Journal of Political Geography, 25(3): 336351.

3. Galbally, J. Alonso-Fernandaez, F. et al, (2012). A high performance fingerprint liveness detection method based on quality related features: Future Generation Computer System, 28 (1): 311-321

4. Hosein, I. (2005). Transforming travel and border controls: Checkpoints in the 
Open Society. Government Information Quarterly, 22 (4): 594-625.

5. Liu, Y. (2009). The principle of proportionality in biometrics: Case studies from Norway. Journal of Computer Law and Security Review, 25 (3): 237-250.

6. Nabti, M and Bouridane, A. (2008). An effective and fast iris recognition system based on a combined multiscale feature extraction technique. Journal of Pattern Recognition, 41 (3): 868-879.

7. Poli, V. Arcot, N. and Charapanamjeri, J. (2009). Evaluation of Biometrics. IJCSNS International Journal of Computer Science and Network Security, 9 (9): 261-269.
8. Shaikh, S and Rabaiotti, J. (2010). Characteristic trade-offs in designing large-scale biometric-based identity management systems. Journal of Network and Computer Applications, 33(2): 63-204.

\section{Online Journals and websites}

Alrai (2011). Evaluation of Fingerprint Mechanism at the Airport. [Retrieved July 20th, 2011] :http://www.alraimedia.com/Alrai/Article Print.aspx?id=274962 in Arabic

Roberts, C. (2005). Biometric. [Retrieved September 16th, 2011], http://www.ccip.govt.nz/newsroom/infor mation-notes/2005/biometrics.pdf 